\title{
Artigo Original / Original Paper \\ As plantas comestíveis no Brasil dos séculos XVI e XVII segundo relatos de época
}

\author{
Edible plants used in Brazil during the $16^{\text {th }}$ and $17^{\text {th }}$ century according to historical reports
}

\author{
Bernardo Tomchinsky ${ }^{1,3}$ \& Lin Chau Ming ${ }^{2}$
}

\begin{abstract}
Resumo
Este trabalho objetivou estudar a flora comestível do Brasil nos séculos XVI e XVII a partir dos textos de 18 autores que estiveram no país durante este período. As plantas citadas foram identificadas por similaridade a partir das descrições textuais e imagens disponíveis nas obras estudadas, considerando a origem, área de ocorrência e nome popular, além da análise de outros estudos botânicos. Ao todo foram levantadas 827 citações de plantas alimentícias nas obras estudadas, das quais foi possível identificar 183 espécies pertencentes a 61 famílias botânicas diferentes. De 37 espécies não foi possível chegar a nenhuma aproximação botânica. Das plantas identificadas, $55 \%$ são nativas das Américas, incluindo as do território brasileiro e de outros países americanos, $8 \%$ são endêmicas e só ocorriam no Brasil, $37 \%$ são exóticas das Américas e duas plantas não tiveram sua origem definida. A partir deste trabalho foi possível observar que havia, durante os séculos XVI e XVII, o uso de uma grande diversidade de espécies na alimentação dos brasileiros, com destaque para a mandioca, abacaxi, jenipapo, batata-doce e milho. A presença de espécies nativas das Américas, mas exóticas do Brasil, como o milho e a batata-doce, evidencia a troca de germoplasma que já existia entre populações indígenas. Nos séculos XVI e XVII ocorreu uma rápida e intensa troca de plantas com outras regiões do mundo promovida pelos europeus, que resultou na introdução de uma grande quantidade de espécies exóticas as quais acabaram ganhando grande importância na dieta dos brasileiros. Por fim, observamos que muitas das plantas citadas estão em desuso até os dias de hoje.
\end{abstract}

Palavras-chave: etnobotânica histórica, história do Brasil, intercâmbio de germoplasma, plantas alimentícias.

\begin{abstract}
This work aimed to study the edible flora in Brazil during the 16th and 17th centuries from analyses of texts of 18 authors who visited the country during this period. The cited plants were identified by similarity through the descriptions and images in the studied texts, area of occurrence, popular name, and the analysis of other botanical studies. In all, 827 citations of food plants were found in the texts studied; it was possible to identify 183 species belonging to 61 different botanical families; 37 citations weren't possible to identify. Of the plants identified, $55 \%$ are native to Americas, including Brazil and other american countries, $8 \%$ are endemic to Brazil, 37\% are exotic to Americas and for two plants it wasn't possible to find their origin. From this data it is possible to say that during the 16th and 17th century there was the use of a great cornucopia of plant species by the brazilian population, especially cassava, pineapple, genipap, sweet potato and corn. The presence of exotic and naturalized species native to the Americas shows the exchange of germplasm that already existed among pre-columbian populations. During the 16th and 17th century there was an intense exchange of plants with other regions of the world promoted by Europeans, which resulted in the introduction of many cultivated and exotic species that became important in the brazilian diet. Finally we can say that many of those plants used during that time are now neglected.
\end{abstract}

Key words: historical ethnobotany, history of Brazil, germoplasm exchange, edible plants.

Veja material suplementar em <https://doi.org/10.6084/m9.figshare.8765492.v1>

${ }^{1}$ Universidade Federal do Sul e Sudeste do Pará, Inst. Estudos em Saúde e Biológicas, Av. dos Ipês s/n, Lot. Cidade Jardim, 68500-00, Marabá, PA, Brasil.

${ }^{2}$ Universidade Estadual Paulista, Faculdade de Ciências Agronômicas, Depto. Horticultura, Fazenda Lageado, Av. Universitária 3780, Altos do Paraíso, 18610-034, Botucatu, SP, Brasil.

${ }^{3}$ Autor para correspondência: btomchinsky@gmail.com 


\section{Introdução}

Quando os europeus desembarcaram no continente americano, já havia ali povos bem estabelecidos com culturas próprias e complexas. Esta população fazia o uso e o manejo dos recursos naturais para a sua sobrevivência, incluindo para a obtenção de medicamentos, ferramentas e alimentos. Clement (1999) estima que a população amazônica já fazia uso de 138 espécies vegetais em diferentes estágios de domesticação naquele período.

Durante o processo de colonização europeia, muitas destas plantas caíram em desuso e esquecimento, enquanto espécies exóticas ganharam grande importância para a população brasileira e outras espécies nativas do Brasil ganharam importância cultural e econômica em outras regiões do globo, no que foi cunhado como o intercâmbio colombiano (Crosby 2003). Antes mesmo deste período, a população nativa, por meio de redes locais de trocas, já fazia o intercâmbio de espécies vegetais com outros grupos americanos (Mann 2005).

Os principais registros escritos que possuímos sobre este período pré-colonial advêm de textos deixados pelos primeiros europeus que visitaram o território hoje delimitado como Brasil durante o inicio da colonização. Estes diários, crônicas e cartas são um rico acervo sobre esta época e, cada qual a seu modo, descrevem costumes das populações nativas, hábitos alimentares, fauna e flora, entre outros aspectos curiosos para os colonizadores. A análise destes documentos, dentro da perspectiva da etnobotânica histórica, é importante para a reconstrução da história do Brasil pré-colonial e para compreender de que forma a flora nativa foi sendo substituída por espécies exóticas e acabou caindo no esquecimento da população geral (Silva et al. 2014).

Os trabalhos existentes que se propõem a analisar os textos históricos deste período se limitam a poucos autores ou estão desatualizados. Frederico Hoehne (1937) em sua obra "Botânica e agricultura no Brasil do século XVI" estuda o trabalho de alguns destes autores, mas todos de forma isolada. Outros botânicos, como Sérgio Millet (D'Abeville 1975), Batista Caetano (Cardim 1978) e Venâncio Willeke (Salvador 1982) analisam nas edições estudadas a botânica presente nas obras, mas muitas de suas indicações se mostraram precipitadas ou desatualizadas. Os únicos autores que possuem trabalhos analisando de forma ampla as plantas indicadas e publicados em periódicos científicos são Piso e Marcgrave (Medeiros \& Albuquerque 2014), sendo que não foram encontradas análises botânicas sobre as obras de Frei Lisboa (1985), Ambrósio Brandão (1997), Gáspar Barléu (1940) e de Pero Lopes Sousa (1839). Kury (2013) de uma forma mais ampla descreve em livro o uso e troca de plantas no Brasil entre os séculos XVI e XIX. Assim, o objetivo deste trabalho é estudar o uso de plantas alimentícias no Brasil dos séculos XVI e XVII e a introdução de espécies exóticas a partir de relatos históricos da época.

\section{Material e Métodos}

Foram consultados textos históricos produzidos por 18 autores que estiveram no Brasil ao longo dos dois primeiros séculos de ocupação europeia, incluindo os trabalhos de Pero Vaz de Caminha, Pero Lopes Souza, Hans Staden, Manuel da Nobrega, José de Anchieta, André Thévet, Jean Léry, Pero de Magalhães Gandavo, Frei Vicente de Salvador, Gabriel Soares Sousa, Ambrósio Fernandes Brandão, Fernão Cardim, Claude d'Abeville, Frei Cristovão de Lisboa, Jorge Marcgrave e Guilherme Piso, Gaspar Barléu e Simão de Vasconcelos. Os trabalhos de Marcgrave e Piso foram analisados conjuntamente, pois os dois estiveram envolvidos no mesmo projeto colonizador e publicaram obras semelhantes em seu conteúdo.

As plantas citadas como comestíveis foram identificadas a partir de similaridade, fazendo o uso das descrições e imagens contidas nos trabalhos estudados, aproximação entre os nomes populares e a análise da área de ocorrência. Também foram considerados outros trabalhos científicos publicados ou notas de botânicos nas edições das obras estudadas, incluindo Frederico Hoehne (1937), Lichtenstein (1961), Alberto Sampaio (Marcgrave 1962), Sérgio Millet (D’Abeville 1975), Batista Caetano (Cardim 1978), Venâncio Willeke (Salvador 1982), Pickel (2008) e Medeiros \& Albuquerque (2014).

Todos os nomes científicos e famílias botânicas foram atualizados de acordo com a Flora do Brasil (2016), as bases de dados The Plant List (2016) e Tropicos (2016). As espécies identificadas tiveram sua origem e ocorrência determinadas a partir das bases de dados da Flora do Brasil (Flora do Brasil 2016), do Herbário Virtual (INCT 2016), do Missouri Botanical Gardens (Tropicos 2016) e literatura especializada. Foram adotadas as seguintes categorias para classificar a origem das plantas: endêmicas (quando só ocorrem 
naturalmente no Brasil), americanas (ocorrem naturalmente no Brasil e/ou em outros países das Américas) e exóticas (com origem em outro país extra-americano). Foi adotada a categoria nativa para qualquer espécie que originalmente é de algum país americano, incluindo ou não o Brasil, a fim de se evitar equívocos, já que o que é reconhecido como o território brasileiro moderno, não existia naquela época. Quando possível, foi identificado o centro de origem de cada planta por região, bioma ou país. Também foi indicado se cada espécie é cultivada ou não, de acordo com os trabalhos estudados ou a partir de fontes secundárias.

A fim de facilitar a análise de dados e evitar equívocos, algumas espécies foram reduzidas a gêneros. Espécies identificadas como etnovariedades ou plantas distintas nas obras consultadas, mas que atualmente se reconhecem como mesma espécie, foram agrupadas, como o caso da mandioca/aipim/ macaxeira (Manihot esculenta Crantz).

A ordem apresentada dos autores estudados foi organizada de acordo com a data em que chegaram ao Brasil. Na sequência ao nome dos autores, entre parênteses, estão o local de nascimento e ano, e o local de morte e ano. A grafia dos nomes populares das plantas levantadas foi mantida como estão nas obras estudadas.

De modo geral, os trabalhos de Ambrósio Fernandes Brandão e Claude d'Abeville são os menos estudados por outros autores, e tiveram uma porcentagem menor de plantas citadas identificadas. Além disto, estes trabalhos apresentam poucas informações que contribuem de modo significativo com a identificação destas plantas. Outros autores, além de possuirem mais ensaios e estudos a respeito (ex. Jorge Marcgrave e Guilherme Piso), relatam o uso de poucas espécies (ex. Hans Staden e Pero Vaz de Caminha), ou descrevem o uso de grande quantidade de espécies exóticas e de fácil identificação (ex. Manuel da Nobrega).

As obras consultados de André Thévet, Frei Cristovão Lisboa, Jorge Marcgrave e Guilherme Piso são ricas em ilustrações, o que facilitou a identificação das plantas descritas. Pela riqueza textual se destaca a obra de Gabriel Soares Sousa, com as descrições "não científicas" mais detalhadas sobre as espécies citadas, incluindo distribuição, ambiente de ocorrência, formas de uso e morfologia da maior parte das plantas citadas.

A observação da área de ocorrência de cada espécie foi importante para confirmar ou contestar outros trabalhos botânicos, que haviam identificado algumas espécies que não ocorrem naturalmente nos locais onde cada autor estivera no Brasil. Da mesma forma, a inaptidão alimentar de certas espécies fez com que elas não fossem consideradas no trabalho.

Existiu certa dificuldade de identificação das plantas citadas a partir de seu nome popular, principalmente no caso dos inhames e carás, que eventualmente se referiam a Dioscoreaceae (Dioscorea L. spp.) ou Araceae, das taiás/ taiobas (Xanthossoma Scott spp.) e dos feijões e favas (Fabaceae). No caso das taiás/taiobas, cuja etimologia se refere a ardido segundo Ramanush (2010), foram todas classificadas como Xanthossoma ssp., já que a presença de rafídes de oxalato de cálcio picantes neste gênero é característica. Ainda entre as Xanthossoma, o nome couve foi adotado algumas vezes e também valeu para Brassica oleracea L. var. acephala DC. Já o nome bredo, adotado por diversos autores, pode estar relacionado a diferentes espécies das famílias Portulacacaeae e Amaranthaceae. Por fim, os feijões e favas foram classificados como Phaseolus sp. ou como Fabaceae, já que alguns trabalhos chegam a citar mais de cinco tipos de feijão e diversos outros de fava.

Foi possível observar uma grande variação do conteúdo entre as obras dos mesmos autores publicadas em diferentes edições, como observa Pickel (2008) nas obras de Piso e Marcgrave. Comparando diferentes edições da mesma obra, existe a supressão de até 18 espécies comestíveis entre elas (Piso 1848; Marcgrave 1943; Piso 1957; Liechtenstein 1961; Pickel 2008; Medeiros \& Albuquerque 2014; Dantas et al. 2017).

Todos os autores estudados ainda descrevem o uso de diversas outras plantas com finalidades distintas (corantes, medicinais, madeira, etc), animais, além de aspectos sociais e geográficos que deveriam ser tema de novos estudos.

\section{Resultados e Discussão}

\section{Autores sobre o Brasil}

nos séculos XVI e XVII

Além da região visitada e das atividades de cada autor, é possível separá-los em grupos de acordo com o país e o processo colonizador a que estavam relacionados. Thévet e Léry estavam viculados à França Antártica e Claude d'Abeville à França Equinocial, enquanto Gaspar Barléu, Jorge Marcgrave e Guilherme Piso participaram do projeto holandês; já os demais autores estavam de alguma forma vinculados ao projeto colonizador português. 
Por formação, os religiosos tiveram grande contribuição com o registro escrito sobre o Brasil da época por meio dos textos de Jean Léry, André Thévet, Manuel da Nobrega, José de Anchieta, Claude d'Abeville, Fernão Cardim, Frei Cristovão Lisboa e Simão de Vasconcelos. De fato, este grupo era a classe intelectual e letrada daquela época, além do caráter missionário de seus trabalhos, registrando todos os costumes locais, em comparação com uma conduta cristã.

Pero Vaz de Caminha (1450, Portugal - 1500, Índia).

Veio ao Brasil em 1500 junto com a armada comandada por Pedro Álvares Cabral que aportou no estado da Bahia. Em sua "Carta do descobrimento do Brasil" de 1500 ele narra ao rei português D. Manuel aspectos sobre esta viagem, os primeiros contatos com a população nativa do Brasil e suas impressões iniciais (Caminha 1876, 1977, 1999).

Caminha relata o consumo de três plantas alimentícias entre as populações indígenas: inhame (Manihot esculenta Crantz), jenipapo (Genipa americana L.) e palmitos (Arecaceae).

Pero Lopes de Sousa (1517, Portugal - 1578, Marrocos).

Irmão de Martim Afonso Sousa, veio ao Brasil em 1530 no que foi considerada a primeira expedição colonizadora do país. Em seu relato descreve a costa do Brasil, desde Pernambuco até a foz do rio da Prata, com incursões no interior a partir do Rio de Janeiro, Cananéia, São Vicente e Rio da Prata (Sousa 1839; Maranhão 2011).

Sousa cita o uso de cinco plantas alimentícias: mandioca (Manihot esculenta), frutas (N.I. - não identificada), milho (Zea mays L.), raízes (N.I.) e palmitos (Arecaceae).

Hans Staden (1525, Alemanha - 1579, Alemanha). Foi um aventureiro/mercenário que veio duas vezes ao Brasil, sendo que durante a segunda, entre 1548 e 1549, foi aprisionado por índios Tupinambá no litoral do estado de São Paulo durante nove meses (Staden 1974, 1999, 2008).

Em sua obra "Duas viagens ao Brasil" (1557), Staden descreve o consumo de cinco plantas, incluindo: sal de palmeira (Arecaceae), getica (Ipomoea batatas (L.) Lam.), mandioca (Manihot esculenta), jenipapo (Genipa americana) e dois tipos de pimenta (Capsicum spp.).
Manuel da Nobrega (1517, Portugal - 1570, Brasil).

Religioso jesuíta, veio ao Brasil em 1549 como missionário junto da armada de Tomé de Sousa. Chegou no estado da Bahia e passou por todo o litoral brasileiro, de Pernambuco à São Vicente. Deixou diversas cartas e textos de cunho religioso sobre o país na época (Serafim 1954).

Nobrega (apud Hoehne 1937), descreve em seus textos sete plantas alimentícias de uso corrente no Brasil: mandioca (Manihot esculenta), figo (Ficus carica L.), açúcar (Saccharum officinarum L.), limão (Citrus limon (L.) Osbeck), laranja (Citrus sinensis (L.) Osbeck), cidra (Citrus medica L.) e uva (Vitis $c f$. vinifera L.).

José de Anchieta (1534, Canárias - 1597, Brasil).

Padre jesuíta, veio ao Brasil em $1553 \mathrm{com}$ a missão de converter os indígenas. Passou por Salvador, mas ficou por estabelecido entre São Vicente, Piratininga (São Paulo) e Rio de Janeiro. Seus textos e cartas registram atividades religiosas, costumes da polução e impressões pessoais (Serafim 1954).

Anchieta (apud Hoehne 1937) descreve 27 plantas usadas como alimento: mandioca (Manihot esculenta), cana-de-açúcar (Saccharum officinarum), laranja (Citrus sinensis), cidra (Citrus medica), mangaba (Hancornia speciosa Gomes), nana (Ananas comosus (L.) Merril), batatas (Ipomoea batatas), sapucaia (Lecythis pisonis Cambess.), araticum (Annona sp.), perexil (Petroselinum crispum (Mill.) Fuss), mocujê (Couma rigida Müll.Arg.), mangará (Xanthosoma sp.), ibâ/pini (Araucaria angustifolia (Bertol.) Kuntze), alface (Lactuca sativa L.), rabão (Brassica napus L.), couve (Brassica oleracea var. acephala DC), melão (Cucumis melo L.), pepino (Cucumis sativus L.), abóbora (Cucurbita máxima Duchesne ex Lam.), cará (Dioscorea sp.), gravanço (Cicer arietinum L.), lentilhas (Lens culinaris Medik.), feijão (Phaseoulus sp.), favas (Fabaceae), limeiras (Citrus aurantifolia (Christm.) Swingle), limoeiros (Citrus limon) e yeticopé (Pachyrhizus tuberosus (Lam.) Spreng.).

André Thévet (1502, França - 1590, França).

Frade franciscano, veio ao Brasil entre 1555 e 1556 na França Antártica de Villegagnon instalada na Bahia da Guanabara. Em seu livro, "Singularidades da França Antártica, e que outros chamam América" (1557), descreveu os costumes dos indígenas e da vida na região. 
Esta obra possui ricas ilustrações de algumas das espécies citadas (Hoehne 1937; Thévet 1944).

Thévet descreve 17 espécies comestíveis, incluindo: nana (Ananas comosus), hetich (Ipomoea batatas), jenipapo (Genipa americana), amendoim (Arachis hypogea L.), pacova (Musa sp.), pimenta (Capsicum sp.), iry (Astrocaryum aculeatissimum (Schott) Burret), hivourahé (Pradosia lactescens (Vell.) Radlk.), mandioca (Manihot esculenta), acaiu (Anacardium occidentale L.), couve (Xanthossoma sp.), horyry (Allagoptera arenaria (Gomes) Kuntze), gerahuva (Arecaceae), palmeira (Arecaceae), feijão (Phaseolus sp.), avati (Zea mays) e favas (Fabaceae).

Jean Léry (1534, França - 1613, Suiça).

Religioso calvinista, veio a França Antártica de Villaganon em 1556. Em sua obra "Viagem a terra do Brasil" (1578) descreve os hábitos dos indígenas e a natureza local (Hoehne 1937; Léry 1961, 1967).

Léry descreve 24 plantas alimentícias de uso no Brasil: nana (Ananas comosus), hetich (Ipomoea batatas), jenipapo (Genipa americana), manobi (Arachis hypogeae), pacoére/paco (Musa sp.), pimentão (Capsicum sp.), iri (Astrocaryum aculeatissimum), hiyuaré (Pradosia lactescens), cana-de-açúcar (Saccharum officinarum), laranja (Citrus sinensis), sabucaié (Lecythis pisonis), morugans (Cucurbita maxima), parreira (Vitis sp.), acaiui (Spondias sp.), cajuá/taioba (Xanthossoma sp.), camdá-uassú (Phaseolus sp.), manjericão (Ocimum basilicum L.), centeio (Secale cereale L.), trigo (Triticum aestivum L.), morgoia (Citrus limon), pimenta (Capsicum sp.), beldroega (N.I.), dois tipos de manihot/aypi (Manihot esculenta) e dois tipos de avati (Zea mays).

Pero de Magalhães Gandavo (1540, Portugal 1579, Portugal).

Historiador português, viajou de Pernambuco a São Vicente. Em suas obras, "Tratado da Terra do Brasil" e "História da província de Santa Cruz" (1576), descreve diversos aspectos sobre o país, incluindo costumes locais, geografia, fauna e flora (Hoehne 1937; Gandavo 1975, 1980, 2008).

Gandavo descreve 21 plantas: ananaz (Ananas comosus), batata (Ipomoea batatas), pimenta (Capsicum sp.), cana-de-açúcar (Saccharum officinarum), laranja (Citrus sinensis), zabucaes (Lecythis pisonis), parreira (Vitis sp.), milho-zaburro (Zea mays), caju (Anacardium occidentale), melão (Cucumis melo), pepino (Cucumis sativus), inhame (Dioscorea sp.), figo (Ficus carica), limão (Citrus limon), bracases/ araçá (Psidium sp.), favas (Fabaceae), feijão (Phaseolus sp.), arroz (Oryza sativa L.), romã (Punica granatum L.), banana/pacova (2) (Musa sp.), e dois tipos de aypim/mandioca/pão-do-brasil (Manihot esculenta).

Vicente do Salvador (1564, Brasil - 1632, Brasil). Jesuíta nascido em Salvador, é considerado o primeiro cronista e historiador brasileiro. Em sua obra publicada em 1627 descreve a "História do Brasil" (Salvador 1982; Oliveira 2008).

Salvador descreve 50 plantas: cajueiro (Anacardium occidentale), inhames-grandes (Dioscorea sp.), taioba (Xanthossoma sp.), pinhão (Araucaria angustifolia), coco (Cocos nucifera L.), palmeiras (Arecaceae), ananás (Ananas comosus), caraguatá (Bromelia antiacantha Bertol.), gytis/ gyitis-coroe (Couepia sp.), batatas (Ipomoea batatas), mandioca (Manihot esculenta), feijão (Phaseolus sp.), favas (Fabaceae), sasapocaias (Lecythis pisonis), milho-zaburro (Zea mays), janipapo (Genipa americana), maçuranduba (Pouteria procera (Mar.) K.Hammer), pimentas (Capsicum sp.), ambaíba (Cecropia sp.), abóbora (Cucurbita moschata Duchesne e C. maxima), cinco tipos de maracujá (Passiflora edulis Sims, P. alata Curtis, P. quadrangulares L., Passiflora spp.), endro (Anethum graveolens L.), coentro (Coriandrum sativum L.), alface (Lactuca sativa), borragem (Borrago officinalis L.), nabo (Brassica rapa L.), couve (B. oleracea var. acephala), celga (Beta vulgaris L.), melancia (Citrulus lanatus (Thunb.) Matsum. \& Nakai), melão (Cucurbita melo), hortelã (Mentha sp.), segurelha (Satureja hortensis L.), figo (Ficus carica), banana-de-são-tomé (Musa sp.), cevada (Hordeum vulgare L.), arroz (Oryza sativa), açúcar (Saccharum officinalis), trigo (Triticum aestivum), romã (Punica granatum), marmelo (Cydonia oblonga Mill.), lima-doce (Citrus aurantifolia), limão (Citrus limon), laranja (Citrus sinensis), cidra (Citrus medica), uva (Vitis sp.) e gengibre (Zingiber officinale Roscoe).

Gabriel Soares Sousa (1540, Portugal - 1591, Brasil).

Chegou ao Brasil em 1565 onde se tornou senhor de engenho no estado da Bahia. Seu "Tratado descritivo do Brasil" publicado em 1587 e "Notícia do Brasil" estão entre as obras mais 
completas do período, com a descrição de hábitos, geografia, cultura, botânica, fauna e administração da colônia no portuguêsa no Brasil (Hoehne 1937; Sousa 1987, 2000).

Sousa descreve 108 espécies alimentícias: beldroega (Amaranthus sp.), espinafre (Spinacia oleracea L.), cebola (Allium cepa L.), alho (Allium sativum L.), cebolinha (Allium schoenoprasum L.), cajú-silvestre (Anacardium humile A.St.Hil.), cajueiro (Anacardium occidentale), cajá (Spondias mombin L.), ambú (Spondias tuberosa Arruda), endro (Anethum graveolens), coentro (Coriandrum sativum), cenoura (Daucus carota L.), nhambi (Eryngium foetidum L.), funcho (Foeniculum vulgare Mill.), salsa (Petrosilum crispum), macugê (Couma rigida), mangabeira (Hancornia speciosa), piquia (Macoubea guianensis Aubl.), taia/taioba (Xanthossoma sp.), mangará (Xanthosoma sp.), urucuri (Syagrus coronata (Mart.) Becc.), japeracaba (Arecaceae), marujaíba (Bactris sp.), pati (Syagrus botryophora (Mart.) Mart.), piçandó (Allagoptera campestres (Mart.) Kuntze.), buri (Arecaceae), patioba (Geonoma pohliana Mart.), anajámirim (Arecaceae), pindoba (Attalea speciosa Mart. Ex Spreng.), palmeira-de-coco (Cocos nucifera), tamareira (Phoenyx dactylifera L.), cardo (Asteraceae), chicória (Cichorium intybus L.), alface (Lactuca sativa), couve-tronchuda (Brassica oleracea var. acephala), nabo (B. rapa), mostarda (Brassica sp.), agrião (Nasturtium officinale), rabano (Brassica sp.), ananás (Ananas comosus), carauatá (Bromelia antiacantha), munducuru (Opuntia fícus-indica (L.) Mill.), mamão (Carica papaya L.), jaracatiá (Jaracatia spinosa (Aubl.) A.DC), piqui (Caryocar sp.), celga (Beta vulgaris), abajeru (Chrysobalanus icaco L.), guti (Licania sp.), bacupari (Garcinia brasiliensis Mart.), melância (Citrulus vulgaris), pepino (Cucumis sativus), abóbora/abóbora-de-quaresma (Curcubita maxima), melão (Cucurbita melo), gerimú (10-12 tipos) (Cucurbita moschata), gerumyê/cabaço (Lagenaria siceraria (Molina) Standl.), cará/inhame (4) (Dioscorea sp.), pino (Fabaceae), amendoim (Arachis hypogea), curuanha (Dioclea sp.), ingá (Inga sp.), favapreta/fava-branca/fava-comanda (Phaseolus lunatus L.), feijão-branco/feijão-preto/feijãovermelho (Phaseolus sp.), poejo (Mentha pulegium L.), hortelão (Mentha sp.), alfavaca (Ocimum gratissimum L.), manjericão (Ocimum basilicum), cupiiba (Vitex sp.), sabucai (Lecythis pisonis), murici (Byrsonimia sp.), mucuri/mocury
(N.I.), mondorurú (Mouriri pusa Gardner), apé (Maclura tinctoria (L.) D.Don ex Steud.), figo-bebera/figueira (Ficus carica), bananeira/ pacoba (Musa sp.), ubucaba (Campomanesia sp.), comichão (Eugenia brasiliensis Lam.), cambuí (Eugenia sp.), cambucá (Myrcia sp.), aracáde-árvore-grande (Psidium guajava L.), araça (Psidium cattleianum Afzel. ex Sabine), maracujá (Passiflora sp.), tanchagem (Plantago sp.), arroz (Oryza sativa), cana-de-açúcar (Saccharum officinalis), ubatim/milho-de-guiné/milho (5 tipos) (Zea mays), beldro (Portulaca oleracea L.), romeira (Punica granatum), jenipapo (Genipa americana), limão-galego (Citrus aurantifolia), limeira (Citrus limon), laranjeira (Citrus sinensis), cidreira (Citrus medica), azamboa (Citrus aurantium L.), limão-francês (Citrus limonia Osbeck), maçarandinba/mandiba (Pouteria sp.), canapu (Physalis pubescens L.), berinjela (Solanum melongena L.), embaíba (Cecropia sp.), araytim (Pouroma sp.), parreira (Vitis vinifera), língua-de-vaca (N.I.), malabar (N.I.), muricana (N.I.), seis tipos de mandioca (Manihot esculenta), seis tipos de pimenta (Capsicum sp.), oito tipos de batata (Ipomoea batatas), maniim (Gossypium barbadense L.) e mangaratia (Zingiber officinale).

Ambrósio Fernandes Brandão (1555, Portugal - 1618, Brasil).

A identificação correta deste autor é até hoje motivo de discussão. Capristiano de Abreu e Mello (Brandão 1997) afirma que ele era um cristão novo que veio ao Brasil entre 1582 e 1618 onde foi senhor de engenho em Pernambuco e na Paraíba. Sua obra, "Diálogos sobre a grandeza do Brasill", publicado em 1618, é ainda pouco estudada em comparação as dos demais autores e foi escrita em formato de diálogo entre dois personagens, abordando diversos aspectos sobre o país, como costumes, geografia e hábitos alimentares (Brandão 1997).

Brandão cita 126 plantas com uso alimentício: macaxeira/mandioca/maniçoba/ farinha-de-pau (Manihot esculenta), arroz (Oryza sativa), abati/milho-de-maçaroca/zaburro (Zea mays), abaiba (Cecropia sp.), abóboras/tquira/ guiné (Cucurbita maxima), acelga (Beta vulgaris), agriões (Nasturtium officinarum R.Br.), alface (Lactuca sativa), alfavaca (Ocimum gratissimum), amendoim (Arachis hypogea), ananáz (Ananas comosus), araça (Psidium sp.), araça-açu (Psidium sp.), araticum (Annona sp.), balancia (Citrulus vulgaris), batata (Ipomoea batatas), beldroegas 
(Portulaca oleracea), berinjela (Solanum melongena), borragam (Borrago officinalis), bredos (N.I.), cabaço (Lagenaria siceraria), cajá (Spondias mombin), cajú (Anacardium occidentale), cana (Saccharum officinalis), inhame (Dioscorea sp.), cará (Dioscorea sp.), cardos (Asteraceae), cenoura (Daucus carota), cheiro (Petrosilum crispum), chícaros (Fabaceae), chicória (Cichoryum intybus), cidra (Citrus medica), coentro (Coriandrum sativum), cominho (Cuminum cyminum L.), couve (Brassica oleracea var. acephala), caruá/curuá (Sicania odorífera (Molina) Standl.), eicajeurs (Cactaceae), enguás (Inga sp.), ervilha (Pisum sativum L.), favas (Phaseoulus lunatus), feijão-guandu (Cajanus Cajans (L.) Millsp.), feijão (Phaseolus sp.), milhonaxenim/massa (Penissetum sp.), feijão-sapotaia (Fabaceae), figo (3) (Ficus carica), funcho (Foeniculum vulgare), gabiraba (Campomonesia sp.), gengibre (Zingiber officinale), gergelim (Sesamum indicum L.), giti (Couepia sp.), goiaba/goivos (Psidium guayava), hicambu/ umbi (Spondias tuberosa), hortelã (Mentha sp.), inhambu (Eryngium foetidum), invira (Xylopia sp.), janamacará (Opuntia sp.), jerimum/jerimumpacova (Cucurbita moschata), laranja (Citrus sinensis), lentinlha (Lens culinaris), limãofrancês (Citrus limonia), limoeira-zamboa (Citrus aurantium), macujé (Couma rigida), marmeleiros (Cydonia oblonga), malagueta (N.I.), pimentas (Capsicum spp.), mamão (Carica papaya), mangava (Hancornia speciosa), manjericão (Ocimum basilicum), maracujá-açu/maracujá/ maracujá-mexira/maracujá-mirim/maracujáperoba (4) (Passiflora spp.), melão (Cucurbita melo), marosis (N.I.), pacoba (Musa sp.), pepinos (Cucumis sativus), quiabo (Abelmoschus esculentus (L.) Moench), rabaçãs (Brassicaceae), raíz de mucuna (Fabaceae), carauatá (Bromelia lacinosa Mart. ex Schult. \& Schult.f.), comari (N.I.), taiá (Xanthossoma sp.), taioba (Xanthossoma sp.), tamarinho (Tamarindus indica L.), tamotarana (Maranta sp.), tatajuba (Maclura tinctoria), toranja (Citrus sp.), tremoço (Lupinus sp.), trigo (Triticum sativum), uti (Licania tomensoa (Benth.) Fritsch), uticroi (Couepia rufa Ducke), uvas (Vitis sp.), passendo (N.I.), coqueiro (Cocos nucifera), pitomba (Talisia esculenta (Cambess.) Radlk.), jabucai (Lecythis pisonis), palmitos (Arecaceae), genipapo (Genipa americana), apê (Annona sp.), ubacropari (Garcinia sp.), comicá (Plinia sp.), ubapitanga (Eugenia sp.), goti (N.I.), garuatá (N.I.), joambos (Myrtaceae), peiti (Arecaceae), canafistula (Fabaceae), guamocá (Myrtaceae), ibamirim (Myrtaceae), uti (N.I.), grexiuruba (Myrtaceae), eicajerus (Cactaceae), ambus (N.I.), ubaperunga (N.I.), pigueás (N.I.), quibado (N.I.), mafai (N.I.), maçaranduba (Sapotaceae), ambusina (N.I.), aquê/coquinho (Arecaceae), comixá (Myrtaceae), erunga (N.I.), passendo (N.I.), umari (Geoffroea spinosa Jacq.), morosis (Byrsonomia sp.) e piquiá (Macoubea guianensis ou Caryocar sp.).

Fernão Cardim (1549, Portugal - 1625, Brasil). Jesuíta português, veio ao Brasil em 1583 e passou pelos estados da Bahia, Pernambuco, Espirito Santo, Rio de Janeiro e São Paulo. Em sua obra "Tratado da terra e gente do Brasil", publicada na década de 1580, aborda diversos aspectos da geografia, história, fauna e flora do Brasil e hábitos locais (Cardim 1978).

Cardim cita 54 plantas: abóbora (Cucurbita maxima), acaju/caju (Anacardium occidentale), aipo (Apium graveolens L.), alface (Lactuca sativa), alho (Allium sativum), aracá (Psidium sp.), araticuá/araticum (Annona sp.), borragem (Borago officinalis), cabaça (Lagenaria siceraria), camará (Lippia sp.), cará (Dioscorea sp.), caraguatá (Bromelia sp.), cebola (Allium cepa), cebollacê (Allium schoenoprasum), cevada (Hordeum vulgare), coentro (Coriandrum sativum), couve (Brassica oleracea var. acephala), endro (Anethum graveolens), ervilha (Pisum sativum), fava (Phaseolus sp.), feijão (Phaseolus vulgaris L.), figueira (Ficus carica), funcho (Foeniculum vulgare), gergelim (Sesamum indicum), ianipaba (Genipa americana), jaboticaba (Myrcia sp.), jaçapucaya (Lecythis pisonis), jambig (Eryngium foetidum), laranjeira (Citrus sinensis), limeira (Citrus aurantiifolia), limoeira (Citrus limon), macuoué (Couma rigida), manjericão (Ocimum basilicum), mandioca (Manihot esculenta), mangába (Hancornia speciosa), mangará (Xanthossoma sp.), maracujá (Passiflora sp.), marmelo (Clydonia oblonga), melão (Cucumis melo), milho (Zea mays), mostarda (Brassica sp.), nabo (Brassica campestres), nana (Ananas comosus), umbu/umbéu/imbú/ambtu (Spondias mombin), hortelã (Mentha sp.), pacoba (Musa sp.), parreira (Vitis vinifera), pepino (Cucumis sativus), pequá/pequiá/piquiá (Caryocar sp.), pimenta (Capsicum sp.), pinheiro/pinheiro-doparaná (Araucaria angustifolia), rabão (Brassica napus var. napobrassica), tajaobas (Xanthossoma sp.) e trigo (Triticum sativum). 
Claude d'Abbeville (?, França - 1632, França).

Foi um frei capuchinho e etimólogo, que veio ao Brasil na França Equinocial (Maranhão) entre 1612 e 1614. Em sua obra "História da missão dos padres capuchinhos na Ilha do Maranhão e suas circunvizinhanças" (1614) descreve animais, plantas, costumes locais e a astronomia indígena (D'Abeville 1874, 1975, 2002).

D'Abbeville cita 67 espécies alimentícias: acaiui/caju-etê/caju-pirã/cajúí/caju-açu (4) (Anacardium spp.), banana (Musa sp.), mangaa (Hancornia speciosa), iaracatia (Jaracatia sp.), uajeruá/ouaieroua/guariruá/uaierona (Couepia sp.), jenipapo/iunipap (Genipa americana), agutitreva/agoutytréua (N.I.), araticu/araticou (Annona sp.), caup/caoup (N.I.), eiuauirap/ euuauirap (Campomanesia sp.), amavie/amavue (Cecropia sp.), goiaba/goyaue (Psidium guajava), margoiá/margoya (Passiflora sp.), palmeira (Cocos nucifera), uäcury/ouacoury/ pindó/uacuri-ruã/ouacouryrouan (Attalea sp.), meuriti-uve (Mauritia flexuosa L.f.), ianajá/ynaia (Attalea maripa (Aubl.) Mart.), carnauba/caranavue (Copernica cerifera), tucon-ive/toucon-vue (Astrocaryum vulgare Mart.), pacuri/pacoury (Platonia insignis), ivá-uaçurã/vua-ouassouran (N.I.), ivá-menbec/vua-membec (Campomonesia sp.), coupuí-aiup (N.I.); acajá/acaiá (Spondias sp.), jarandá/yacaranda (N.I.), umbu/onbou (Spondias tuberosa), apajurá/paioura (Couepia sp.), uvácave/vua-caue (Myrtaceae), pitom (Talisia esculenta), avenonbui-acaju/auenonbouih-acaiou (Calophyllum brasiliense Cambess.), iachicha/ yachichá (Eugenia sp.), cajueêm (Myrtaceae), macajé-iva/maukaié-vue (Couma Utilis (Mart.) Müll.Arg.), uagiru/ouagirou (Chrysobalanus icaco), moreci/morecy (Byrsonimia sp.), amiiu/ amyou (Lucuma caimito), mururé/mourouré (N.I.), uiá-ojiú/vua-oyiou/uyua-yyiu (Eugenia sp.), uiá-pirip/vua-pirub (Campomonesia sp.), omei/onemery (Poraqueiba sp.), araça/arasa (Psidium sp.), uiti/outy (Licania sp.), pequeí/pekey (Caryocar sp.), jutaí/ioutay (Hymenea sp.), jatáiva/yata-vua (Hymenea sp.), ingá (Inga sp.), ananás (Ananas comosus), caruatá/karouata (Bromelia cf. antiacantha.), jaramacuru/yarammacarou (Cereus cf. jamaracu), giromon (Cucurbita cf. maxima), taker/kaker (Cucurbita cf. moschata), ivá-eém/ vua-éen (Citrulus vulgaris), comandá-açu/ commanda (Fabaceae), comanda-mirí (Fabaceae), jeteich/yeteuch/patate (3) (Ipomoea batatas), cará (Dioscorea sp.), taiáiaçu (Xanthossoma sp.), maduí/mandou (Arachys hypogea), manioc/ manioch/macachet/manioca-etê/manioc-cane (4) (Manihot esculenta), usenpopuita/vsenpopouytan (N.I.), avati (Zea mays), melão (Cucumis melo), favas (Fabaceae), vagem (Fabaceae), lentilhas (Lens culinaris), pimenta (Capsicum sp.) e canade-açúcar (Saccharum officinarum).

Frei Cristovão Lisboa (Portugal, 1583 - Portugal, 1652).

Chega ao Brasil em 1624 e fica entre o Maranhão, Pará, Ceará e Pernambuco, após a expulsão dos franceses, como evangelizador e inquisitor até o ano de 1635. Em sua obra "História dos animais e árvores do Maranhão" de 1631, estão reunidas imagens sobre a flora e fauna local; entretanto alguns autores apontam que elas teriam sido aproveitadas de desenhos deixados pelos franceses após a reconquista de Portugal (Lisboa 1985; Peixoto \& Escudeiro 2002).

Lisboa descreve 49 plantas comestíveis: dois tipos de mandioca (Manihot esculenta), três de cará (Dioscorea trifida), tamotarana (Maranta sp.), mendoim (Arachis hypogea), gitica (Ipomoea batatas), jeremu (Cucurbita moschata), hubaém (Citrulus vulgaris), cinco tipos de comenda (Phaseolus spp.), camendagora (Fabaceae), iá (Lagenaria siceraria), sapucaia (Lecythis pisonis), araçarainha (N.I.), jenipapo (Genipa americana), ibonguiva (Pachira aquática Aubl.), amingua (Duguetia sp.), iaraquatica (Jacaratia sp.), uvaixainha (Eugenia sp.), aracá (Psidium sp.), quaiú (Anacardium occidentale), paquory (Mammea americana L.), murici (Byrsonimia sp.), caia (Spondias sp.), cinco castas de quiinha (Capsicum sp.), maraquiaia-açu (Passiflora sp.), maracujaí (Passiflora sp.), maroguoauomerim (Passiflora sp.), inambucaru (Passiflora sp.), ubapeva (Passiflora sp.), maracujá (duas espécies) (Passiflora spp.), (Passiflora sp.), mamão (Carica papaya), pacoveira (Musa sp.), biriba (Annona mucosa), araçá-açu (Psidium sp.), araçá-una (Psidium sp.), pindobaíte (Attalea sp.), anai (Attalea sp.), tucum (Bactris sp.), moreti (Mauritia flexuosa), comanacaru (Cereus sp.), mangaveira (Hancornia speciosa), sequeriba (Protium sp.), anhaúba (Bertholetia excelsa Bonpl.) e ananás (Ananas comosus).

Jorge Marcgrave (1610, Alemanha - 1644, Angola).

Guilherme Piso (1611, Holanda - 1678, Holanda). Marcgrave e Piso foram responsáveis pela primeira publicação de cunho científico sobre o 
Brasil. Naturalistas, vieram ao nordeste do país na comitiva do Brasil Holandês de Maurice de Nassau entre 1638 e 1644 . Na "Historia naturalis brasiliae" (1648), descrevem animais, plantas, doenças e remédios (Piso 1848; Marcgrave 1943; Piso 1957; Liechtenstein 1961; Pickel 2008; Medeiros \& Albuquerque 2014; Dantas et al. 2017).

Marcgrave e Piso listam 117 plantas comestíveis, incluindo: caponga (Sesuvium portulacastrum (L.) L), caruru/bredo (Amaranthus sp.), perexil (Blutaparon vermiculare (L.) Mears), caciaiba/acaiuiba (Anacardium occidentale), aroeira (Schinus terebenthifolius Raddi), acaia/ ibametara (Spondias purpurea L.), umbu (Spondias tuberosa), copiiba (Tapirira guianensis Aubl.), araticu-ponhe (Annona sp.), araticum-apê (Annona sp.), mangabiba/mangaiba (Hancornia speciosa), nhambi (Eryngium foetidum), pequeá (Macoubea guianensis ou Caryocar sp.), taioba (Xanthossoma cf. violaceum), taioba (Xanthossoma cf. sagittifolium), aniga-iba (Montrichardia linifera (Arruda) Schott), pindoba/ inaia/pindova (Attalea oleifera), inaia-guacuiba/ coqueiro (Cocos nucifera), carna-iba/ananá-chicarirí (Copernica prunifera (Mill.) H.E.Moore), aririr/brejauba/airi (Astrocaryum aculeatissimum), tucum (Astrocaryum vulgare), pindoba/inaiá (Attalea compta), tamara (Phoenix dactylifera), ioçara/palmito-doce (Euterpe edulis Mart.), miriti (Mauritia flexuosa), aqué/catolé (Syagrus comosa (Mart.) Mart.), urucuriiba/urucury (Syagrus coronata), iraibá (Syagrus oleraceae (Mart.) Becc.), maraiáiba (Arecaceae), cuite/cochine (Crescentia cujete L.), urucu (Bixa orellana L.), nana/ananás (Ananas comosus), nanabrava/ caraguatá-acanga (Bromelia sp.), iamacarú/ cardon/caxambu (Cereus jamacaru DC.), iamacarú (Cactaceae), iamacarú (Brasilipuntia brasiliensis Willd. A.Berger), iamacarú (Cereus fernambucencis Lem.), meerú (Canna indica L.), tapiá (Crataeva tapia L.), mamoeira/ papay/mamão/pinoguaçu (Carica papaya), iaracatiá (Jaracatia spinosa), guaieru/guajeru (Chrysobalanus icaco), guitiiba (Couepia rufa), micambe-de-angola (Cleome cf. pentaphylla L.), coapoiba/pao-gamelo (Clusia nemorosa G.Mey.), ibacuri-pari (Platonia insignis Mart.), ibacuri-pari (Garcinia macrophylla Mart.), guaiacum/ibiraée (Pradosia sp.), ietica/ quiquoaquianputu/ batata/ omenapó-yeima/ pararo (3) (Ipomoea batatas), jaee/balancia (Citrulus lanatus), pepino-silvestredo-brasil (Cucumis cf. anguria L.), iurum/bóbora/ pompoen (Cucurbita cf. moschata), melão (Cucumis melo), curuba/curuá (Sicania odorifera) cará/inhame-de-são-thomé/quiquoaquicongo (Dioscorea cf. trifida L.f.), maniiba/amdijba/ mandioca (9) (Manihot esculenta), maniçoba/ mandijba (Manihot sp.), mundubi (Arachis hypogaea), comanda-guira (Cajanus cajan), umari (Geoffroea spinosa), jetaiba (Hymenaea sp.), ingá (Inga sp.), mandatia (Lablab purpureus (L.) Sweet), ietropé (Pachyrizus sp.), ibiruba (Eugenia cf. brasiliensis), mandubi-d'angola (Vigna subterrânea (L.) Verdc.), guando (Phaseolus lunatus), cumanda-miri (Phaseolus vulgaris), cumanda-guaçu (Canavalia ensiformis (L.) DC), mucuna-guaçu (Dioclea sp.), tamarando. iutay (Tamarindus indica), aglutiguepo-obi/ acutitiguepo/cotitepooba (Heliconia sp.), ibapurunga (Vitex sp.), iaçapucaya (Lecythis pisonis), mureci/mureci-petinga/mureci-guacú (4) (Byrsonima sp.), quigombó/quilombo/ malva-moscada (Abelmoschus sp.), tamoatarana (Maranta sp.), caaghiyuyo (Clidemia hirta (L.) D.Don), curuiri (Mouriri pusa), muira (Henriettea succosa (Aubl.) DC.), tataiiba (Maclura tinctoria), pacoeira/quibuaaquitiba (Musa paradisiaca), ibabiraba (Campomaneisa sp.), ibipitanga/ubapitanga (Eugenia uniflora L.), araça-miri (Psidium araca); araça-iba/ araça-guaçú (Psidium guineense), guayaba/ granaet-peeren (Psidium guajava), cambui (Myrtaceae), iabuticaba (Plinia cauliflora (Mart.) O.Berg.), golfo (Nymphaea amazonum Mart. \& Zucc.), murucujá (Passiflora cincinnata), murucuia-guaçu/gauinumbi-acaiuba (Passiflora quadrangularis), murucuia (Passiflora alata), sésamo/gangila/girgilim (Sesamum indicum), nhandú/betre (Piper marginatum Jacq.), vubae/ tacomaree (Saccharum officinarum), caaponga (Portulaca oleracea), ianipaba/ienipapo (Genipa americana), limão-galego (Citrus aurantifolia), nhua/pitoma (Talisia esculenta), guiti-toroba/ steen-appel (Pouteria grandiflora (A.DC.) Baehni), guyti-iba (Licania sp.), maçarandíba (Manilkaria salzmanni (A.DC.) H.J.Lam.), taquera (Lagenaria sicenaria), quiya-uçu/pimentagrande/pimentões (Capsicum sp.), quiya-cumari/ quiyaquia/pimenta-malagueta (12) (Capsicum spp.), camarú (Physalis sp.), iuati (Solanum agrarium), belingela/macumba/tongu (Solanum melongena), acetosa (Talinum paniculatum (Jacq.) Gaertn.), ambaíba (Cecropia sp.), caraguatá (N.I.), jua-umbu (Ximenia americana L.) e uma erva (N.I.). 
Gaspar Barléu (1584, Holanda - 1648, ?).

Historiador e teólogo, veio ao Brasil holandês de Maurice de Nassau. Escreveu sua obra baseado nas conquistas da Holanda nas Américas e na África narrando batalhas, geografia e costumes locais (Barléu 1940).

Barléu cita 34 plantas comestívies: banana/ pacoba (Musa sp.), acajá (Anacardium occidentale), açúcar (Saccharum officinalis), ananases (Ananas comosus), batata-doce (Ipomoea batatas), cocos (Arecaceae), feijoal (Phaseolus sp.), gengibre (Zingiber officinale), jenipapo (Genipa americana), laranja (Citrus sinensis), limão (Citrus limon), mandiocal (Manihot esculenta), maracujá (Passiflora sp.), melância (Citrulus vulgaris), melão (Cucurbita melo), milho (Zea mays), pepinos (Cucumis sativus), pimenta (Capsicum sp.), sapucaia (Lecythis pisonis), taioba (Xanthossoma sp.) e uva/vinha (Vitis sp.), limão-grande (Citrus sp.), limão-doce (Citrus sp.), romã/romeira (Punica granaturm), mamão (Carica papaya), mangabeira (Hancornia speciosa), uvalheira (Eugenia sp.), palmeiras (Arecaceae), pitangeiras (Eugenia sp.), araticuns (Annona sp.), jamacarus (Cereus sp.), tamarindeiros (Tamarindus indica), castanheiros (N.I.) e tamareiras (Phoenyx dactylifera).

Simão de Vasconcelos (Portugal, 1597 - ?, 1671). Religioso, sua obra "Noticias curiosas e necessárias das coisas do Brasil" publicada em 1668, aborda a história da América portuguesa, mas ainda é pouco estudada em comparação as demais obras (Vasconcelos 1668).

São citadas 41 plantas: acayá/caju (Anacardium occidentale), açúcar (Saccharum officinalis), ananás (Ananas comosus), araçazeiro (Psidium sp.), araticum (3) (Annona sp.), aypi/ mandioca (Manihot esculenta), bachoripari (Garcinia sp.), batata/jetica (Ipomoea batatas), cajazeiros (Spondias mombin), canafistulashorteses/bais (N.I.), canelas (N.I), sapucaya (Lecythis pisonis), cará (Dioscorea sp.), çaragoçanas (N.I.), cagaguata (Bromelia sp.), gengibre (Zingiber officinale), goiabeira (Psidium guayava), guta (N.I.), iaboticaba (Myrcia sp.), iamacarú/urumbeba (Opuntia sp.), iapinabeiro (Genipa americana), ibicuybas/nóz-moscada (Myristicaceae), igbánemixama (Eugenia sp.), inhame (Dioscorea sp.), mangabeira (Hancornia speciosa), mangará (Xanthossoma sp.), maracujá (Passiflora sp.), milho (Zea mays), mocujé (Couma rigida), pacoba/bananeira (Musa sp.), palmeiras (Arecaceae), quatro tipos de pimentas (Capsicum sp.), pinheiros-brasílicos (Araucaria angustifolia), pitangueira (Eugenia uniflora), pitombeira (Talisia esculenta), tajóba (Xanthossoma sp.), taratinho (N.I.), umbu (Spondias tuberosa) e vinho (Vitis sp.).

\section{Plantas mais citadas}

Ao todo, nas obras dos 18 autores estudados, foram levantadas 827 citações de plantas comestíveis disponíveis no Brasil nos séculos XVI e XVII. Foi possível identificar 183 espécies pertencentes a 61 famílias botânicas; de 37 citações não foi possível chegar a nenhuma aproximação botânica (Apêndice 1, disponibilizado no link $<$ https://doi.org/10.6084/ m9.figshare.8765492.v1 >).

As famílias com maior número de citações foram a Areaceae, seguida pela Fabaceae, Cucurbitaceae, Poaceae, Solanaceae, Myrtaceae e Rutaceae. Estas famílias também correspondem a algumas das com maior número de espécies ocorrendo no Brasil (BFG 2018). Já Rutaceae e Poaceae, que também estão entre as mais citadas, possuem entre seus representantes diversas espécies com origem exótica do Brasil.

Seguindo o principio de que as espécies mais salientes e citadas por um maior número de autores seriam as mais relevantes para a população local, é possível afirmar que a mandioca, citada em todos os trabalhos estudados, era a planta mais importante na alimentação do Brasil do século XVI/XVII. Em sequência aparecem como mais citadas o abacaxi, batata-doce e jenipapo, citadas em 13 trabalhos cada uma; feijões/favas, banana e pimentas, citadas em 12 trabalhos cada; caju, taias/taiobas, inhames (Dioscorea), sapucaia, cana-de-açucar e milho em 11 trabalhos cada; e mangaba, laranja, maracujás e uvas em nove trabalhos.

É possível que algumas espécies pouco citadas também tinham na época grande importância econômica regional, mas não tiveram destaque neste trabalho por não serem frequentes nos ambientes descritos pelos autores estudados. Desta forma, são pouco citadas espécies de ocorrência exclusiva na Amazônia, nos Pampas e no Pantanal, em comparação com espécies de ocorrência na Caatinga, na Mata Atlântica ou no Cerrado, biomas onde estes autores estiveram. Neste sentido, o umbu (Spondias tuberosa) e a carnaúba (Copernica prunifera), endêmicas da caatinga e do nordeste, só aparecem em trabalhos de autores que estiveram nesta região; enquanto a castanheira (Bertolhettia excelsa) está apenas no trabalho de Frei Cristovão Lisboa, que realizou incursões na região amazônica a partir de Belém do Pará. Já a araucária (Araucaria 
angustifolia) é citada por autores que estiveram nas regiões meridionais do Brasil, como José de Achienta, Vicente Salvador, Fernão Cardim e Simão de Vasconcelos. Outro fator que deve ser considerado é que estes autores estabeleceram contato principalmente com indígenas do tronco Tupi-Guarani e Macro-Gê (Tapuias) que ocupavam na época a faixa litorânea do Brasil (Ribeiro 2009), o que possivelmente influênciou na saliência das plantas nativas mais citadas e que deviam estar na dieta destas populações.

Fatores como o cultivo e a acessibilidade a estas plantas também podem ter influenciado na saliência das espécies citadas. Entre as 23 mais citadas, apenas uma não era cultivada, evidenciando como este fator (cultivo) está diretamente relacionado a acessibilidade, uso e saliência das plantas citadas. Neste sentido, também é interessante considerar o número de variedades citadas de cada planta. Provavelmente, espécies com um maior número de variedades eram cultivadas, estavam num processo mais avançado de domesticação e possuíam maior importância local. Desta forma, as pimentas do gênero Capsicum, os feijões/favas, a batata-doce, o cajueiro, abóboras, milhos, tubérculos do gênero Xanthossoma e Dioscorea e a mandioca deveriam estar entre as plantas mais importantes para a população brasileira no período, já que possuíam um maior número de variedades, segundo os autores estudados.

É importante considerar que cada autor estudado possuia objetivos específicos com seus textos. Gabriel Soares Souza escreveu sua obra para enaltecer as riquezas do Brasil com a intenção de conseguir empréstimos junto à metrópole para seus empreedimentos no Brasil e desta forma se dedica a descrever o maior número de espécies nativas que consegue. Já Piso e Marcgrave, como naturalistas, enfocam sobre espécies nativas e seus diversos usos. Por sua vez, José Anchieta e Manoel da Nobrega não tinham como interesse prioritário descrever a natureza do Brasil, mas sim a sua população, costumes e religiosidade, e citam uma maior quantidade de plantas exóticas.

Entre as plantas com maior destaque, a sapucaia, que é citada por 11 autores e ocorre em praticamente todos os biomas do país (Flora do Brasil 2016), foi uma das que aparece em maior desuso, sendo praticamente impossível encontrála atualmente em mercados ou na natureza, seja por esquecimento ou pela devastação das matas onde ocorria. Entre as mais citadas, o jenipapo, as taias/taiobas, a mangaba e os inhames (Dioscorea) são sencontradas apenas regionalmente hoje em dia (Brasil 2015). Outras espécies nativas menos citadas raramente são encontradas em mercados.

\section{Categorias de plantas comestíveis}

As plantas estudadas foram separadas em diferentes categorias de acordo com a forma de consumo (hortaliças, condimentos, in natura, bebidas) e a parte utilizada (raízes, caule e folhas e frutos e sementes). As raízes cultivadas possuíam grande importância na alimentação da época, com a mandioca, a batata-doce, as Xanthossoma spp., o cará e o umbu (que fornece raízes em épocas de escassez, além de seus frutos), entre as plantas mais citadas.

Os frutos consumidos crus (in natura), representados por diversas espécies da família Myrtaceae, Anacardiaceae, Annonaceae, Arecaceae, entre outras, também tinham grande importância para a alimentação da população local. Entretanto, com raras exceções, como o jenipapo, o cajueiro e a mangaba, as frutíferas nativas e arbóreas eram menos cultivadas em comparação a outras plantas nativas e herbáceas, como as raízes comestíveis já citadas e as pimentas do gênero Capsicum. Também é possível observar que as espécies exóticas eram mais cultivadas do que as nativas, até mesmo por que sua introdução dependia do seu cultivo.

De forma isolada, a única hortaliça folhosa nativa consumida, ainda que não crua, era a taioba (Xanthossoma spp.). São ainda indicados como hortaliças os bredos e beldroegas (Amaranthus sp. e Portulaca olercacea) e outras espécies com menos citações, porém é difícil contextualizar se sua introdução ou consumo foram realizadas pelos europeus ou se já eram realizados pela população nativa. Katz et al. (2012) observaram que ainda hoje o consumo de hortaliças é escasso entre populações indígenas da região amazônica.

Com exceção das pimentas do gênero Capsicum, poucas outras plantas são citadas como condimento pelos autores estudados, assim como observa Cascudo (2011). Hans Staden descreve os diversos usos das pimentas Capsicum, suas variedades, seu preparo em pó e o uso do sal elaborado com as cinzas de uma palmeira, a qual o consumo excessivo, observa, torna as pessoas doentes. Thévet também descreve o processo de obtenção do sal, por meio da evaporação da água marinha, que era misturada com a pimenta pilada para tempero. Entretanto, ele faz ressalva de que entre os negociantes europeus o pimentão tinha valor 
apenas para a tinturaria. Outra planta condimentar, citada por quatro autores, é o jambug/jambig (Eryngium foetidum), que teria a propriedade de "queimar" a língua, além de atributos medicinais. Brandão faz menção ao potencial aromático da envira (Xylopia sp.), enquanto Gabriel Soares Sousa descreve árvores que crescem nas florestas semelhantes a noz-moscada. Frei Lisboa ainda indica o maraquaia-açu (Passiflora sp.), que diz que é cheia de um licor e pimenta muito azeda que servia para fazer vinagre para comer com peixe. Já Piso e Marcgrave fazem mais menções a plantas condimentares nativas, seu potencial aromático e na conservação de alimentos como a Xylopia sp., o Schinus sp. e Piper marginatum, além das pimentas Capsicum.

Talvez este pouco interesse português pelas plantas condimentares do Brasil tenha sido motivado pelo fato de que Portugal se dedicava a época do comércio com as Índias, quando ainda detinha este monopólio das especiarias. Neste período a metrópole proibia o cultivo no Brasil de qualquer especiaria que viesse a concorrer com os seus produtos asiáticos (Kury 2013). Gabriel Soares Sousa relata que o cultivo de gengibre era proibido no Brasil pela coroa portuguesa.

Outra categoria de uso citada frequentemente é de bebidas alcoólicas e vinhos elaborados com a fermentação de diversos tipos de plantas, incluindo a mandioca, batata-doce, milho, caju, frutíferas e palmeiras, sendo uma forma popular de consumo entre a população local. Seria possível aprofundar a discussão sobre a importância histórica do consumo de bebidas fermentadas em comunidades tradicionais do Brasil, já que estas podem estar relacionadas a festividades e atividades de socialização (Albuquerque 2011; Almeida 2015), além de permitir o consumo de alimentos potencialmente tóxicos (mandioca), facilitar a sua digestão e garantir sua inocuidade (Marsh et al. 2014).

É interessante observar que algumas espécies, apesar de conhecidas por mais autores, não eram reconhecidas como comestível por todos. O urucum é mencionado em diversas obras, mas aparece indicado como comestível apenas por Piso e Marcgrave. Outras plantas que aparecem desta forma são Eryngium foetidum, Lagenaria sicenaria, Lippia spp. e a Crescentia cujete, descritas por diversos autores, mas citadas em outras categoria de uso que não alimentícia, sugerindo que o uso destas plantas variou ao longo do tempo e de região para região.
Quanto ao preparo de doces e sobremesas com o emprego de diversos frutos e raízes e a adição de açúcar, parece que foi uma tradição europeia a partir da introdução da cana-de-açúcar e a instalação de engenhos no nordeste do país (Antonil 1982; Freyre 1997; Cascudo 2011).

Brandão, Piso e Marcgrave mencionam algumas plantas consumidas exclusivamente em período de escassez, incluindo a raíz da mucuna (Fabaceae), macambira (Bromeliaceae), folhas da mandioca, Montrichardia linifera, umari (Geoffrea spinosa), raíz do umbu e a raiz de uma Heliconia, algumas das quais exigiam preparo específico para permitir seu consumo.

Alguns autores também faziam distinção entre as plantas de acordo com a sua origem ou ao grupo que fazia o seu consumo. Gabriel Soares Sousa chama as hortaliças europeias de frutos do reino. Marcgrave e Piso distinguem sete plantas consumidas e introduzidas pelos escravos de origem africana, além de outras 21 indicadas como de consumo exclusivo dos indígenas.

Muitas das plantas citadas estão em desuso e esquecimento, sendo apresentadas como comestível apenas nestes trabalhos estudados e sem outras referências em publicações mais recentes consultadas. É possível que alguns dos fatores que tenham possibilitado este processo foram a substituição das plantas nativas por espécies exóticas ou cultivadas, a homogeneização da dieta da população, a modificação e o desmatamento das áreas de ocorrência destas plantas, ou ainda que o consumo delas estavam relacionados a momentos específicos e de dificuldade. Ao mesmo tempo algumas espécies apresentadas em outras categorias e não como comestíveis nos trabalhos estudados, como o urucum (corante e medicinal), a Acmella (medicinal) e o Hibiscus sabdarifera (medicinal), atualmente são importantes na culinária regional brasileira (Brasil 2015), demonstrando como este processo histórico é complexo e dinâmico.

\section{Origem das plantas citadas}

Foi possível identificar a origem de 183 espécies levantadas neste trabalho; destas, 14 (8\%) são endêmicas do Brasil, 97 (55\%) são nativas das Américas, ocorrendo naturalmente no Brasil e/ou em outros países do continente, e $65(37 \%)$ são exóticas das América. Apesar desta generalização para espécies americanas, é possível observar que algumas destas, com origem fora do atual território brasileiro, incluindo a batata-doce, nativa da América Central e Oeste 
da América do Sul, o milho, nativo da América Central, algumas espécies de Capsicum, abóboras e os feijões (Phaseolus vulgaris), aparecem com destaque desde os primeiros trabalhos, sugerindo sua introdução durante o período pré-colombiano. Estudos linguísticos com diversas "proto-línguas" americanas mostram que o milho, o feijão e as pimentas Capsicum já estavam bem distribuídos em todo o continente americano no período précolombiano (Brown et al. 2013, 2014a,b). Também foram encontradas evidências paleobotânicas do cultivo de milho na Amazônia peruana há mais de 6.000 anos atrás (Bush et al. 2016). Todos estes indícios comprovam o complexo e intenso sistema de trocas entre populações indígenas que habitavam o continente americano, conforme apontou Mann (2005).

É interessante observar que muitas espécies exóticas foram introduzidas ao longo dos primeiros anos de colonização europeia e alcançaram papel importante na economia e cultura local (Tab. 1). A bananeira (Musa sp.) originária do sudeste asiático e introduzida ao longo das primeiras décadas de colonização teve rápida dispersão em todo o Brasil e chegou a ser considerada nativa por alguns dos primeiros cronistas. $\mathrm{O}$ registro mais antigo da bananeira nas Américas foi realizado por Frei Tomás de Berlanga na Ilha de Hispañola (São Domingos) em 1516 (Langdon 1993). Gandavo via nela o sinal da cruz e dizia que a presença da bananeira no Brasil era um sinal de que aquela terra era parte do paraíso bíblico. Algumas plantas exóticas, como a própria bananeira e a cana-de-açúcar, ganharam tamanha importância que foram incorporadas na mitologia e cosmologia de alguns povos indígenas (Albert \& Milliken 2009; Kopenawa \& Albert 2015).

A partir dos relatos estudados é possível identificar em qual período cada espécie exótica foi introduzida no país (Tab. 1). Com esta cronologia, observamos que várias plantas exóticas (extraamericanas) já haviam sido introduzidas pelos europeus até o final do século XVI. Entretanto, é necessário ponderar que com esta análise não é possível precisar em qual evento cada espécie foi introduzida, até porque durante este período diversas embarcações portuguesas e de outras nações margeavam a costa brasileira (Belluzzo 2000; Maranhão 2011; Kury 2013). É consenso que a primeira missão colonizadora portuguesa no Brasil com o intuito de ocupar de forma sistemática o território brasileiro foi realizada por Martim de Lopes Sousa entre 1530 e 1532, quando foram trazidas várias espécies exóticas para aclimatação e cultivo no Brasil (Maranhão 2011).

Tabela 1 - Primeira citação de espécies exóticas das Américas no Brasil.

Table 1 - First citation of exotic plants introduced in Brazil.

\begin{tabular}{ll}
\hline Ano do trabalho e autor & Plantas \\
\hline 1548 (Manuel da Nobrega) & Citrus sinensis; Saccharum officinarum; Citrus limon; Citrus medica; Vitis sp.; Ficus carica \\
1553 (José de Anchieta) & $\begin{array}{l}\text { Cucumis melo; Cucumis sativus; Lactuca sativa; Brassica oleracea var. acephala; Brassica } \\
\text { napus; Citrus aurantiifolia; Petroselinum crispum; Lens culinaris; Cicer arietinum; Vicia faba }\end{array}$ \\
1555 (André Thévet) & Musa sp. \\
1556 (Jean Léry) & Triticum aestivum; Secale cereale; Lagenaria siceraria; Ocimum basilicum \\
1576 (Pero de M. Gandavo) & Oryza sativa; Punica granatum \\
1564 (Vicente do Salvador) & Coriandrum sativum; Mentha sp.; Citrullus lanatus; Zingiber officinale; Beta vulgaris; \\
& Anethum graveolens; Borago officinalis; Cydonia oblonga; Satureja hortensis \\
1565 (Gabriel Soares Sousa) & $\begin{array}{l}\text { Foeniculum vulgare; Cocos nucifera; Solanum melongena; Daucus carota; Cichorium } \\
\text { intybus; Nasturtium officinale; Ocimum gratissimum; Citrus limonia; Citrus aurantium; }\end{array}$ \\
& $\begin{array}{l}\text { Allium cepa; Allium sativum; Brassica } \text { sp.; Spinacia oleracea; Phoenix dactylifera; Raphanus } \\
\text { sp.; Mentha pulegium }\end{array}$ \\
1582 (Ambrósio F. Brandão) & $\begin{array}{l}\text { Pisum sativum; Sesamum indicum; Cajanus cajan; Abelmoschus esculentus; Tamarindus } \\
\text { indica; Lupinus sp.; Pennisetum sp.; Citrus maxima }\end{array}$ \\
1583 (Fernão Cardim) & Allium schoenoprasum; Hordeum vulgare; Apium graveolens \\
& Lablab purpureus; Vigna subterranea
\end{tabular}


Manuel da Nobrega em 1548 foi o primeiro autor a descrever uma grande quantidade de espécies exóticas (extra-americanas) no país. Existem registros do cultivo de trigo e marmelo na província de Piratininga (atual cidade de São Paulo), que teriam sido os primeiros produtos de exportação de São Paulo para outras regiões do país. Já a uva era cultivada no nordeste e sudeste com até três colheitas em um ano, de acordo com as podas realizadas na cultura, segundo exalta Ambrósio Fernandes Brandão. Estas informações revelam que naquela época já havia uma agricultura sofistica baseada em espécies exóticas e adaptada às condições climáticas brasileiras.

Do mesmo modo que várias espécies exóticas foram introduzidas no continente americano durante o intercâmbio promovido pelos colonizadores europeus, espécies americanas também foram transportadas para outras regiões do mundo, onde assumiram importante papel econômico e cultural (Crosby 2003; Mann 2011; Laws 2015). A "Summa de árvores e plantas da índia intra Gázes", do início do século XVII e de autoria de Manuel Godinho de Erédia, ilustra o cajueiro, a papaya, a goiaba e o ananaz, todas de origem americana, na flora Malaia (Kury 2013) enquanto a "Flora sinensi" de 1.656, também lista estas mesmas espécies ocorrendo na China (Michael 1656).

\section{Conclusões}

Este trabalho permite resgatar aspectos sobre a alimentação da população brasileira dos séculos XVI e XVII a partir dos trabalhos estudados. Cada obra analisada traz abordagens distintas de acordo com seus autores. De modo geral, havia durante os séculos XVI e XVII o uso de uma grande diversidade de plantas na alimentação dos brasileiros, incluindo ao menos 183 espécies vegetais, das quais 55\% eram nativas do Brasil, com destaque para a mandioca, abacaxi, jenipapo, caju, taiobas, carás e sapucaia, além das americanas e naturalizadas batata-doce, pimentas Capsicum, feijões e milho, e das exóticas cana-de-açúcar e bananeira. Durante este período ocorreu um grande intercâmbio de plantas com outras regiões do mundo promovido pelos europeus. Também foi possível constatar que já havia no Brasil diversas espécies exóticas do país e nativas das Américas já cultivadas e naturalizadas, evidenciando a intensa troca entre as populações durante o período precolombiano. Por fim podemos observar que muitas das espécies citadas caíram em desuso e raramente são encontradas nas regiões de origem. É possível que novos estudos sobre os trabalhos analisados tragam outras informações para contribuir com este debate.

\section{Agradecimentos}

Agradecemos à CAPES a bolsa de Doutoramento do primeiro autor e ao CNPq a bolsa de Produtividade outurgada ao segundo autor. Agradecemos também as preciosas colaborações dos revisores e editores destacados para o processo de avaliação e editoração deste artigo.

\section{Referências}

Albert B \& Milliken W (2009) Urihi A: a terra-floresta Yanomami. Instituto Socioambiental, São Paulo. $207 p$.

Albuquerque MBB (2011) Beberragens tupinambá e processo educativos no Brasil colonial. Educação em Revista 27: 19-44.

Almeida FO (2015) A arqueologia dos fermentados: a etílica história dos Tupi-Guarani. Estudos Avançados 29: 87-118.

Antonil AJ (1982) Cultura e opulência do Brasil. Editora Itatitiaia, Belo Horizonte. 214p.

Barléu G (1940) História dos feitos recentemente praticados durante oito anos no Brasil e noutras partes sob o governo do ilustríssimo João Maurício Conde de Nassau. Ministério da Educação, Rio de Janeiro. 435p.

Belluzzo AMM (2000) O Brasil dos viajantes. Metalivros, São Paulo; Editora Objetiva, Rio de Janeiro. 192p.

Brandão AF (1997) Diálogos das grandezas do Brasil (1618). FUNDAJ, Editora Massangana, Recife. $242 \mathrm{p}$.

Brasil (2015) Alimentos regionais brasileiros. Ministério da Saúde, Brasília. 484p.

Brown CH, Clement CR, Epps P, Luedeling E \& Wichmann S (2013) The paleobiolinguistics of domesticated chili pepper (Capsicum spp.). Ethnobiology Letters 4: 1-11.

Brown CH, Clement CR, Epps P, Luedeling E \& Wichmann S (2014a) The paleobiolinguistics of maize (Zea mays L.). Ethnobiology Letters 5: 52-64.

Brown CH, Clement CR, Epps P, Luedeling E \& Wichmann S (2014b) The paleobiolinguistics of the commom bean (Phaseolus vulgaris L.). Ethnobiology Letters 5: 104-115.

Caminha PV (1876) A carta de achamento do Brasil. Manuscrito do Barão de Santa Angelo. 27p.

Caminha PV (1977) A carta de Pero Vaz de Caminha. Comentada por Prado JFA. Editora Agir, Rio de Janeiro. 114p. 
Caminha PV (1999) Carta a el rey D. Manuel. Transcrita e comentada por Villela MA. Ediouro, São Paulo. $97 \mathrm{p}$.

Cardim F (1978) Tratado da terra e gente do Brasil (15831601). Traduzido e comentado por de Caetano B, Abreu C \& Garcia R. Editora Nacional, São Paulo. $259 \mathrm{p}$.

Cascudo C (2011) História da alimentação no Brasil. Editora Global, São Paulo. 972p.

Clement C (1999) 1492 and the loss of amazonian crop genetic resources. Economic Botany 53: 188-202.

Crosby AW (2003) Colombian exchange: biological and cultural consequences of 1492. Greenwood Publishing Group. 282p.

D’Abeville C (1874) História da missão dos padres capuchinhos na ilha do Maranhão e suas circunvizinhanças. Typ. do Frias, São Luiz do Maranhão. 459p.

D’Abeville C (1975) História da missão dos padres capuchinhos na ilha do Maranhão e terras circunvizinhas (1632). Editora Itatiaia, Belo Horizonte. 297p.

D’Abeville C (2002) História da missão dos padres capuchinhos na ilha do Maranhão e suas circunvizinhanças. Siciliano, São Paulo. 363p.

Dantas MKM, Santos CAG \& Medeiros MFT (2017) Reports of knowledge and the uses of cactaceae species in the historia naturalis brasiliae (1648): comparative past-present analyses. Ethnoscientia 2: 1-19.

Flora do Brasil (2016) Jardim Botânico do Rio de Janeiro. Disponível em < http://floradobrasil.jbrj.gov.br/ $>$. Acesso em 5 janeiro 2017

Freyre G (1997) Açúcar: uma sociologia do doce, com receitas de bolos e doces do Nordeste do Brasil. Cia. das Letras, São Paulo. 215p.

Gandavo PM (1980) Tratado da terra do Brasil. História da província de Santa Cruz (1576). Editora Itatiaia, Belo Horizonte; Editora da Universidade de São Paulo, São Paulo.150p.

Gandavo PM (2008) Tratado da terra do Brasil e história da província de Santa Cruz, a que vulgarmente chamamos Brasil. Senado Federal, Brasília. 161p.

Hoehne FC (1937) Botânica e agricultura no Brasil no Século XVI. Cia editora nacional, São Paulo. 410p.

INCT (2016) Herbário Virtual da Flora e dos Fungos. disponível em $<$ http://inct.florabrasil.net/herbariovirtual/>. Acesso em 20 dezembro 2016.

IPNI (2016) International Plants Names Index. Disponível em <www.ipni.org>. Acesso em 14 dezembro 2016.

Katz E, Léopez CL, Fleury M, Miller RP, Payê V, Dias T, Silva F, Oliveira Z \& Moreira E (2012) No greens in the forest? Note on the limited consumption of greens in the amazon. Acta Societatis Botanicorum Poloniae 81: 283-293.

Kopenawa D \& Albert B (2015) A queda do céu: palavras de um Xamã Yanomami. Cia. das Letras, São Paulo. $729 \mathrm{p}$.
Kury LB (2013) Uso e circulação de plantas no Brasil - Séculos XVI-XIX. Andrea Jakobson, Rio de Janeiro. 324p.

Langdon R (1993) The banana as a key to early American and Polynesias history. The Journal of Pacific History 28: 15-35.

Laws B (2015) Fifty plants that changed the course of history. Firefly books, Richmond Hill. 224p.

Léry J (1961) Viagem à terra do Brasil. Editora Biblioteca do Exército, Rio de Janeiro. 250p.

Léry J (1967) Viagem à terra do Brasil. Livraria Martins, São Paulo. 279p.

Lichtenstein MHK (1961) Estudo crítico dos trabalhos de Marcgrave e Piso sobre a história natural do Brasil a luz dos desenhos originais. Brasiliensia Documenta, São Paulo. 305p.

Lisboa FC (1985) História dos animais e árvores do maranhão (1625-1631). Editora Alambra, Rio de Janeiro. 204p.

Mann CC (2005) 1491 Novas revelações das américas antes de Colombo. Editora Objetiva, São Paulo. $460 \mathrm{p}$.

Maranhão R (2011) Diários de navegação pero Lopes e a expedição de Martim Afonso de Sousa (1530-1532). Editora terceiro nome, São Paulo. 244p.

Marcgrave J (1943) História natural do Brasil. Com comentários de botânica de Sampaio AJ. Imprensa Oficial do Estado, São Paulo. 293p.

Marsh AJ, Hill C, Ross RP \& Cotter PD (2014) Fermented beverages vith health-promoting potential: past and future perspectives. Trends in Food Science \& Technology 38: 113-124.

Medeiros MFT \& Albuquerque UP (2014) Food flora in the 17 th century northeast region of Brazil in Historia Naturalis Brasilae. Journal of Ethnobiology and Ethnomedicine 10: 50.

Michael B (1656) Flora Sinensis, fructus floresque humillime porrigens, [...] in publicum a $\mathrm{R} P$ Michaele Boym, [...],". Disponível em $<$ http:// neptun.unamur.be/items/show/1>. Acesso em 5 janeiro 2017.

Oliveira ML (2008) A história do Brasil de Frei Vicente Salvador: história e política no Império Português do Século XVII. Editora Versal, Rio de Janeiro; Odebrecht, São Paulo. 585p.

Peixoto AL \& Escudeiro A (2002) Pachira aquática (Bombacaceae) na obra "História dos animais e árvores do Maranhão" de frei Critovão de Lisboa. Rodriguesia 53 (82): 123-130.

Pickel BJ (2008) A flora do nordeste do Brasil segundo Piso e Marcgrave no século XVII. EDUFRPE, Recife. 312p.

Piso G (1957) História natural a médica da índia ocidental em cinco livro. Traduzido e anotado por Mário Lobo Leal. Ministério da Educação e Cultura, Instituto Nacional do Livro, Rio de Janeiro. 685p.

Piso G (1848) História natural do Brasil ilustradas. Cia. Editora Nacional, Rio de Janeiro. 434p. 
Ramanush N (2010) Nheegatu-tupi: vocabulário e gramática tupi-guarani. Editora STS, São Paulo. $109 \mathrm{p}$.

Ribeiro B (2009) O índio na história do Brasil. Editora Global, São Paulo. 141p.

Salvador V (1982) História do Brasil (1500-1627). Abreu C, Garcia R, Willeke V (orgs.) Editora Itatiaia, Belo Horizonte; Editora da Universidade de São Paulo, São Paulo. 437p.

Serafim L (1954) Cartas do primeiros jesuítas do Brasil V1 (1538-1553). Comissão do IV centenário da Cidade de São Paulo, São Paulo. 576p.

Silva TC, Medeiros PM, Balcázar AL, Araújo TAS, Pirondo A \& Medeiros MFT (2014) Historical ethnobotany: an overview of selected studies. Ethnobiology and Conservation 3: 1-12.

Sousa GS (1987) Tratado descritivo do Brasil em 1587. Comentada por Varganhagem FA. Editora Nacional, São Paulo. 389p.

Sousa GS (2000) Tratado descritivo do Brasil em 1587. Comentada por Varganhagem FA. Editora Itatiaia, Belo Horizonte. 302p.
Sousa PL (1839) Diário da navegação de Pero Lopes Souza. Typografia da sociedade propagadora dos conhecimento úteis, Lisboa. 130p.

Staden H (1974) Duas viagens ao Brasil (1557). Editora Itatiaia, Belo Horizonte; Editora da Universidade de São Paulo, São Paulo. 218p.

Staden H (1999) A verdadeira história dos selvagens, nus e ferozes devoradores de homem (1548-1555). Dantes, Rio de Janeiro. 190p.

Staden H (2008) Duas viagens ao Brasil. Editora Itatiaia, Belo Horizonte. 215p.

The Plant List (2016) Disponível em <www.theplantlist. com>. Acesso em 15 dezembro 2016.

Thévet A (1944) Singularidades da França Antártica, o que outros chamam América. Editora Nacional, São Paulo. 502p.

Tropicos (2016) Missouri Botanical Gardens Database. Disponível em <www.tropicos.org $>$. Acesso em 15 novembro 2016.

Vasconcellos PS (1668) Noticias curiosas e necessárias das coisas do Brasil. Officina de Ioam da Costa, Lisboa. 289p. 